ISSN. 2775-4324 (Online)

Journal of Physical Activity and Sports

Volume 2, Nomor 2, Agustus 2021, 274-279

Journal of Physical Activity and Sports

\title{
Pengaruh Latihan Kekuatan Otot Tangan, Daya Tahan Otot dan Keseimbangan Terhadap Ketepatan Shooting Game Petanque di UKM Petanque Upgris
}

\author{
Wawan Adi Saputro ${ }^{1}$, Osa Maliki ${ }^{2}$, Fajar Ari Widiyatmoko \\ ${ }^{123}$ Program Studi Pendidikan Jasmani Kesehatan dan Rekreasi, Fakultas Pendidikan \\ Ilmu Pengetahuan Sosial dan Keolahragaan, Universitas PGRI Semarang \\ Jl. Sidodadi Timur No 24 - Dr. cipto, Semarang, \\ Jawa Tengah, 50125 \\ * Coressponding Author. E-mail wawanadisaputro1@gmail.com
}

\begin{abstract}
This research is motivated by the problem in this study, namely weak hand muscle strength, muscle endurance and balance to shooting games, there are some UPGRIS students who take part in Petanque UKM, some of them are students who have hand muscle strength, muscle endurance in throwing something is lacking and so is the balance of the body. The purpose of this study was to determine the effect of hand muscle strength, muscle endurance and balance on the accuracy of shooting games at UKM Petanque UPGRIS and to determine the causes of the lack of accuracy in shooting game Petanque. The method used is quantitative research methods with the type of research model True-Experimental Design Pre-test Post-test Two Group design. The population and sample in this study were 10 petanque athletes at the PGRI University of Semarang. This sampling technique uses total sampling. The method of data analysis used paired sample test with a significance level of $5 \%$. The results showed that there was an effect of hand muscle strength training, muscle endurance and balance on the accuracy of shooting game Petanque which was expressed through the results of hypothesis testing with paired sample t-test with tcount $=-7.571$ and ttable $=2.777$. Then $\mathrm{t} \_$count $>$ttable so that Ho is rejected and $\mathrm{Ha}$ is accepted, while based on the significance value because the value is sig. $=0.002$ with a confidence level of $95 \%$, then Sig. $>\alpha(0.05)$. So that Ho was rejected. The conclusion of this study is that there is an effect of hand muscle strength training, muscle endurance and balance on the accuracy of the Petanque shooting game at the UKM Petanque UPGRIS club. Suggestion, hand muscle strength training, muscle endurance and balance are used as training media, so that it can help athletes improve shooting accuracy.
\end{abstract}

Keywords: Hand muscles, muscle endurance, shooting accuracy balance

\begin{abstract}
Abstrak
Penelitian ini dilatar belakangi oleh masalah pada penelitian ini yaitu lemahnya kekuatan otot tangan, daya tahan otot dan keseimbangan terhadap shooting game, ada beberapa Mahasiswa UPGRIS yang mengikuti UKM Petanque dari beberapa mahasiswa ada yang kategorinya Mahasiswa yang mempunyai kekuatan otot tangan, daya tahan otot pada lemparan ada yang kurang dan begitupun dengan keseimbangan tubuh. Tujuan dari penelitian ini untuk mengetahui pengaruh kekuatan otot tangan, daya tahan otot dan keseimbangan terhadap ketepatan shooting game di UKM petanque UPGRIS dan untuk mengetahui penyebab kurangnya ketepatan shooting game petanque. Metode yang digunakan yaitu metode penelitian kuantitatif dengan jenis model penelitian True-Eksperimental Design Pre-test Post-test Two Group design. Populasi dan sampel dalam penelitian ini adalah atlet petanque Universitas PGRI Semarang yang berjumlah 10 atlet. Teknik sampling ini menggunakan total sampling. Metode analisis data menggunakan uji paired sample test dengan taraf signifikansi 5\%. Hasil penelitian menunjukkan ada pengaruh latihan kekuatan otot tangan, daya tahan otot dan keseimbangan terhadap ketepatan shooting game petanque yang dinyatakan melalui hasil uji hipotesis dengan uji paired sample t-test dengan $\mathrm{t} \_$hitung $=-7,571$ dan $\mathrm{t} \_$tabel $=2,777$. Maka t_hitung $>\mathrm{t} \_$tabel sehingga Ho ditolak dan Ha diterima, sedangkan berdasarkan nilai signifikansi karena nilai sig. $=0,002$ dengan tingkat kepercayaan 95\% maka Sig. $>\alpha(0,05)$. Sehingga Ho ditolak. Simpulan penelitian ini adalah Ada pengaruh latihan kekuatan otot tangan, daya tahan otot dan keseimbangan terhadap ketepatan shooting game Petanque di klub UKM Petanque UPGRIS. Saran, latihan kekuatan otot tangan, daya tahan otot dan keseimbangan digunakan sebagai media latihan, sehingga dapat membantu atlet meningkatkan ketepatan shooting.
\end{abstract}

Kata Kunci : Otot tangan, daya tahan otot, keseimbangan ketepatan shooting 


\section{PENDAHULUAN}

Olahraga Petanque adalah suatu bentuk permainan olahraga yang tujuannya melempar bola sedekat mungkin dengan bola sasaran. Kaki pelempar juga harus berada didalam lingkaran kecil yang sudah ditentukan. Ada jarak yang ditetapkan yaitu jarak lemparan ke bola sasaran antara jarak enam sampai Sembilan meter. Dalam Petanque terdapat nomor single tim, double tim, triple tim, dan mix tim. Olahraga Petanque adalah olahraga yang peminatnya tergolong sedikit karena olahraga tersebut termasuk olahraga baru. Oleh sebab itu tujuan dari penelitian ini adalah untuk mengetahui pengaruh kekuatan otot tangan, daya tahan otot dan keseimbangan terhadap ketepatan shooting. Dengan menggunakan penelitian ini bertujuan untuk mengetahui pengaruh latihan kekuatan otot tangan, daya tahan otot dan keseimbangan terhadap ketepatan shooting game Petanque di klub UKM Petanque UPGRIS. Penelitian ini dilakukan karena masih lemahnya kekuatan otot tangan, daya tahan otot dan keseimbangan terhadap shooting game, ada beberapa Mahasiswa UPGRIS yang mengikuti UKM Petanque dari beberapa mahasiswa ada yang kategorinya Mahasiswa yang mempunyai kekuatan otot tangan, daya tahan otot pada lemparan ada yang kurang dan begitupun dengan keseimbangan tubuh. Untuk melakukan shooting pada permainan Petanque dibutuhkan akurasi atau ketepatan yang sangat baik. Dengan penelitian ini diharapkan kita bisa mengetahui seberapa besar pengaruh kekuatan otot tangan, daya tahan otot dan keseimbangan terhadap ketepatan shooting game Petanque agar bisa menghasilkan akurasi yang baik pada saat melakukan shooting.

\section{METODE}

Penelitian ini menggunakan desain penelitian true eksperimental design dalam bentuk pre-test, treatment, post-test. Dalam penelitian ini menggunakan Purposive Sampling. Jumlah sampel dalam penelitian ini adalah 10 responden. Dalam penelitian ini teknik pengumpulan data dengan menggunakan pre-test, treatment, post-test, dokumentasi. Adapun teknik analisis data yang digunakan dalam penelitian ini adalah teknik analisis statistik menggunakan uji-t. Adapun rumus yang digunakan adalah sebagai berikut:

Uji normalitas merupakan analisis statistik yang pertama kali dilakukan dalam rangka analisis data. Analisis data dapat dilanjutkan apabila data berdistribusi normal. Pengujian normalitas sebaran data menggunakan Kolmogorov-Smirnov Testdengan bantuan SPSS 16. Jika nilai p > 0,05 maka data normal, akan tetapi sebaliknya jika hasil analisis menunjukkan nilai $\mathrm{p}<0,05$ maka data tidak normal. (Sugiyono 2007 : 107) Untuk menguji normalitas dengan menggunakan rumus :

$$
x^{2}=\sum_{=}^{k} \frac{(f o-f h)}{f h}
$$

Keterangan :

$$
\begin{aligned}
& x^{2}: \text { Chi Kuadrat } \\
& \text { fo: Frekuensi yang diobservasi } \\
& \text { fh: Frekuensi yang diharapkan }
\end{aligned}
$$


Uji Homogenitas dilakukan dengan menggunakan uji $\mathrm{F}$ atau anova tes, jika hasil analisis menunjukkan $\mathrm{p}>0,05$ maka data tersebut homogen, akan tetapi jika hasil analisis data menunjukkan nilai $\mathrm{p}<0,05$ maka data tersebut tidak homogen. (Sugiyono 2011: 125)

Keterangan :

$$
F=\frac{\text { varians terbesar }}{\text { varians terkecil }}
$$

$\mathrm{F}=$ Nilai $\mathrm{f}$ yang dicari

Uji Hipotesis

Pengujian hipotesis ini menggunakan uji-t dengan bantuan prgram SPSS 16 yaitu dengan membandingkan mean antara kelompok 1 (pretest) dan kelompok 2 (posttest). Apabila nilai thitung < ttabel, maka Ha ditolak, jika thitung > besar dianding ttabel maka Ha ditolak, jika thitung > besar dibanding ttabel maka Ha diterima.

Analisis yang tepat untuk digunakan dalam penelitian ini adalah paired samples t-test. Teknik analisis ini menggunakan dua kelompok tetapi anggota dari dua kelompok tersebut sama. Dalam penelitian ini ada dua kelompok, yaitu kelompok sebelum diberi perlakuan (metode pelatihan untuk memperkuat otot tangan, daya tahan otot, dan keseimbangan dengan alat yang telah disiapkan) dan setelah diberi perlakuan (metode pelatihan untuk memperkuat otot tangan, daya tahan otot, dan keseimbangan dengan alat yang telah disiapkan). Karena hanya ada satu UKM, yaitu UKM Petanque Universitas PGRI Semarang maka anggota sama. Melalui uji paired samples t-test, ketika ada perbedaan yang signifikan antara rata-rata nilai pretest dan posttest dibutuhkan uji N-gain score. Uji ini bertujuan untuk mengetahui efektivitas penggunaan suatu metode atau perlakuan (treatment) tertentu dalam penelitian one group pretest-posttest design. N-gain score dapat dihitung dengan berpedoman pada rumus di bawah ini :

$$
N \text { Gain }=\frac{\text { skor posttest }- \text { skor pretest }}{\text { skor ideal }- \text { skor pretest }}
$$

Keterangan : Skor ideal adalah nilai maksimal (tertinggi) yang dapat diperoleh

Kategorisasi perolehan nilai $N$-Gain score dapat dijadikan dalam bentuk persen (\%). Adapun contoh pembagian kategori perolehan nilai $N$-Gain terdapat pada tabel di bawah ini.

Tabel 1. Kategori Tafsiran Efektivitas $N$-Gain

\begin{tabular}{|l|l|}
\hline Presentase (\%) & Tafsiran \\
\hline$<40$ & Tidak Efektif \\
\hline $40-55$ & Kurang Efektiv \\
\hline $56-75$ & Cukup Efektiv \\
\hline$>76$ & Efektiv \\
\hline
\end{tabular}

Sumber: Hake, R.R, 1999 


\section{HASIL DAN PEMBAHASAN}

Penelitian yang dilakukan untuk mengetahui pengaruh kekuatan otot tangan, daya tahan otot dan keseimbanagan terhadap hasil ketepatan shooting, dengan sampel penelitian yang dijadikan responden yaitu atlet UKM Petanque Upgris sebanyak 10 orang, yang dibagi menjadi 2 kelompok. Kelompok kontrol sebanyak 5 atlet yang tidak diberikan latihan kekuatan otot tangan, daya tahan otot dan keseimbangan sedangkan kelompok eksperimen sebanyak 5 atlet yang diberikan latihan kekuatan otot tangan, daya tahan otot dan keseimbangan.

Tabel 2. Peningkatan Rata-Rata Hasil Ketepatan Shooting

\begin{tabular}{|c|c|c|c|c|c|}
\hline \multirow{2}{*}{$\begin{array}{c}\text { Kelompok } \\
\text { Responden }\end{array}$} & Atelier & \multicolumn{2}{|c|}{$\begin{array}{c}\text { Rata-Rata Ketepatan } \\
\text { Shooting }\end{array}$} & $\begin{array}{c}\text { Selisih Rata- } \\
\text { Rata }\end{array}$ & $\begin{array}{c}\text { Peningkatan } \\
(\%)\end{array}$ \\
\cline { 2 - 6 } & Pretest & Posttest & & \\
\hline \multirow{4}{*}{$\begin{array}{c}\text { Kelompok } \\
\text { Kontrol }\end{array}$} & Jarak 6 m & 1 & 1,6 & 0,6 & $2,5 \%$ \\
\cline { 2 - 6 } & Jarak 7 m & 0,6 & 2 & 1,4 & $5,7 \%$ \\
\cline { 2 - 6 } & Jarak 8 m & 1,4 & 0,6 & 0,8 & $3,4 \%$ \\
\cline { 2 - 6 } & Jarak 9 m & 0 & 0 & 0 & $0 \%$ \\
\cline { 2 - 6 } & Keseluruhan & 2,8 & 4,2 & 1,4 & $6,3 \%$ \\
\hline \multirow{3}{*}{$\begin{array}{c}\text { Kelompok } \\
\text { Eksperimen }\end{array}$} & Jarak 6 m & 1,6 & 3,8 & 2,2 & $9,4 \%$ \\
\cline { 2 - 6 } & Jarak 7 m & 0,8 & 2,8 & 2 & $8,3 \%$ \\
\cline { 2 - 6 } & Jarak 8 m & 0,2 & 1,8 & 1,6 & $6,5 \%$ \\
\cline { 2 - 6 } & Jarak 9 m & 0 & 0,8 & 0,8 & $3,2 \%$ \\
\cline { 2 - 6 } & Keseluruhan & 2,6 & 9,2 & 6,6 & $29,5 \%$ \\
\hline
\end{tabular}

Sumber : Data primer penelitian yang diolah (2020)

Berdasarkan hasil analisis data dengan paired sample t-test, uji hipotesis hasil ketepatan shooting pada kelompok kontrol diperoleh nilai $\mid$ Thitung $|=|-2,064 \mid<$ Ttabel $(2,777)$ dan Sig. $(0,108)>$ $\alpha$ (0.05). yang berarti tidak terdapat pengaruh kekuatan otot tangan, daya tahan otot dan keseimbangan pada ketepatan shooting game petanque pada kelompok kontrol pada UKM Petanque Upgris. Sedangkan uji hipotesis hasil ketepatan shooting pada kelompok eksperimen diperoleh nilai $\mid$ Thitung $|=|-7,571 \mid>$ Ttabel $(2,777)$ dan Sig. $(0,02)<\alpha(0.05)$. yang berarti terdapat pengaruh kekuatan otot tangan, daya tahan otot dan keseimbangan pada ketepatan shooting game petanque pada kelompok eksperimen pada UKM Petanque Upgris. Dimana pemberian latihan kekuatan otot tanggan, daya tahan otot dan keseimbagan efektif meningkatan rata-rata hasil ketepatan shootingg dari rata-rata pretest sebesar 2,60 naik menjadi 9,20.

Peningkatan rata-rata hasil ketepatan shooting pada kelas kontrol atlet UKM Petanque Upgris secara keseluruhan dari jarak 6 meter sampai 9 meter sebesar 6,3\%. Sedangkan peningkatan rata-rata hasil ketepatan shooting pada kelas eksperimen yang diberikan latihan kekuatan otot tangan, daya tahan otot dan keseimbanagan pada atlet UKM Petanque Upgris secara keseluruhan dari jarak 6 meter sampai 9 meter sebesar 29,5\%. Sehingga dapat disimpulkan bahwa pemberian latihan kekuatan otot 
tangan, daya tahan otot dan keseimbangan efektif menigkatkan hasil ketepatan shooting pada olahraga petanque.

Penelitian ini didukung oleh penelitian terdahulu yang dijadikan referensi oleh peneliti, salah satunya penelitian yang dilakukan oleh Wahyu Widodo dan Abdul Hafidz mengenai kontribusi panjang lengan, koordinasi mata tangan dan konsentrasi terhadap ketepatan shooting pada olahraga petanque .

\section{KESIMPULAN}

Berdasarkan penelitian dapat disimpulkan bahwa hipotesis hasil ketepatan shooting pada kelompok kontrol diperoleh nilai $\mid$ Thitung $|=|-2,064 \mid<$ Ttabel $(2,777)$ dan Sig. $(0,108)>\alpha(0.05)$. yang berarti tidak terdapat pengaruh kekuatan otot tangan, daya tahan otot dan keseimbangan pada ketepatan shooting game petanque pada kelompok kontrol pada UKM Petanque Upgris. Sedangkan uji hipotesis hasil ketepatan shooting pada kelompok eksperimen diperoleh nilai |Thitung|=|-7,571| > Ttabel $(2,777)$ dan Sig. $(0,02)<\alpha(0.05)$. yang berarti terdapat pengaruh kekuatan otot tangan, daya tahan otot dan keseimbangan pada ketepatan shooting game petanque pada kelompok eksperimen pada UKM Petanque Upgris. Dimana pemberian latihan kekuatan otot tanggan, daya tahan otot dan keseimbagan efektif meningkatan rata-rata hasil ketepatan shootingg dari rata-rata pretest sebesar 2,60 naik menjadi 9,20.

Peningkatan rata-rata hasil ketepatan shooting pada kelas kontrol atlet UKM Petanque Upgris secara keseluruhan dari jarak 6 meter sampai 9 meter sebesar 6,3\%. Sedangkan peningkatan rata-rata hasil ketepatan shooting pada kelas eksperimen yang diberikan latihan kekuatan otot tangan, daya tahan otot dan keseimbanagan pada atlet UKM Petanque Upgris secara keseluruhan dari jarak 6 meter sampai 9 meter sebesar 29,5\%. Sehingga dapat disimpulkan bahwa pemberian latihan kekuatan otot tangan, daya tahan otot dan keseimbangan efektif menigkatkan hasil ketepatan shooting pada olahraga petanque.

\section{DAFTAR PUSTAKA}

Ahmad Nasrulloh. (2012). Pengaruh Latihan Circuit Weight Training Terhadap Kekuatan Dan Daya Tahan Otot. Yogyakarta : Universitas Negeri Yogyakarta.

Akhmad Hidayatullah Al Arifin. (2012). Implementasi Pendidikan Multikultural Dalam Praksis Pendidikan Di Indonesia. Sleman : Madrasah Tsanawiyah Negeri Sleman.

Ardo Okilanda. (2018). Revitalisasi Masyarakat Urban/Perkotaan Melalui Olahraga Petanque. Palembang : Universitas PGRI Palembang.

Ayuk Tyas Agustina Dan Anung Priambodo. (2017). Hubungan Antara Tingkat Konsentrasi Tehadap Hasil Ketepatan Shooting Olahraga Petanque Pada Peserta UNESA Petanque Club. Surabaya : Universitas Negeri Surabaya.

Caca Ica Saleh. (2012). Aturan Petanque. Jakarta : Organisasi Olahraga Petanque Indonesia. 
Dede Khoirunnisa Agustini dkk. (2018). Hubungan Kekuatan Otot Lengan Dan Koordinasi Mata Tangan Terhadap Ketepatan Shooting Dalam Olahraga Petanque Di Club Kota Sukabumi Tahun 2018. Sukabumi : Universitas Muhammadiyah Sukabumi.

Desi Adityo Hermawan Dan Hari Amirullah Rachman. (2018). Pengaruh Pendekatan Latihan Dan Koordinasi Mata Tangan Terhadap Ketepatan Shooting Peserta Ekstrakulikuler Basket. Yogyakarta : Universitas Negeri Yogyakarta.

Fajar Ari Widiyatmoko. (2017). Strategi Implementasi Nilai Pendidikan Dalam Pembelajaran Penjas Dikaji Dari Perspektif LPTK. Semarang : Universitas PGRI Semarang.

Indrayogi Dan Bhakti Muda Heryanto. (2018). Pengembangan Model Pembelajaran Shooting Dalam Permainan Bola Basket. Majalengka : Universitas Majalengka.

Muhammad Abdul Kharim Dan Nurkholis. (2018). Analisis BACKSWING Dan Release Ketepatan Pointing Half Lob Jongkok Pada Jarak 7 Meter Olahraga Petanque. Surabaya : Universitas Negeri Surabaya.

Nukhrawi Nawir. (2011). Kontribusi Kekuatan Otot Tangan Dan Daya Tahan Otot Lengan Dengan Kemampuan Memanah Jarak 30 Meter Pada Atlet Panahan Sulawesi Selatan. Sulawesi Selatan: FIK UNM.

Ramdan Pelana. (2016). Hubungan Kekuatan Otot Tungkai Dan Keseimbangan Statis Dengan Hasil Shooting Pada Atlet Club Petanque. Jakarta : Universitas Negeri Jakarta.

Ratnasari Rohmah. (2018). Pengaruh Latihan Wall Shooting Dan One Hand Shooting Terhadap Hasil Shooting Free Throw Ekstrakulikuler Bola Basket Putra Di SMK Negeri 4 Semarang.Semarang : Universitas PGRI Semarang.

Setiawan Adi Marzuna Dan Sudarso. (2019). Pengaruh Media Audio Visual Terhadap Hasil Belajar Shooting Bola Basket Kelas XI AK 4 SMK Negeri 2 Tuban. Surabaya : Universitas Negeri Surabaya.

Sofyan Hadi Dan Fifukha Dwi Khory. (2013). Survei Pendidikan Jasmani, Olahraga, Dan Kesehatan Pada Satuan Pendidikan SD, SMP, SMANegeri Se-Kecamatan Karangan Kabupaten Trenggalek. Trenggalek : Universitas Negeri Surabaya.

Sugiyono. (2012). Metode Penelitian Kuantitatif, Kualitatif, dan R\&D. Bandung : Alfabeta

Syahrudin Warta Kusuma Cucu Pradana Dan Nurkholis. (2018). Kontribusi Tinggi Badan, Panjang Lengan, Keseimbangan, Konsentrasi Dan Persepsi Kinestetik Terhadap Ketepatan Shooting Pada Olahraga Petanque. Surabaya : Universitas Negeri Surabaya

Tatang Iskandar Dan Fahmi Rahman. (2018). Pengaruh Metode Latihan Hand Grip Terhadap Kekuatan Genggaman Tangan Pada Atlet Putra Pelatcab Petanque Kota Bekasi. Bekasi : Universitas Islam 45 Bekasi

Tri Sutrisna dkk. (2018). Model Latihan Keterampilan Shooting Olahraga Petanque Untuk Pemula. Jakarta : Universitas Negeri Jakarta.

Wahyu Widodo Dan Abdul Hafidz. (2018). Kontribusi Panjang Lengan, Koordinasi Mata Tangan, Dan Konsentrasi Terhadap Ketepatan Shooting Pada Olahraga Petanque. Surabaya : Universitas Negeri Surabaya. 